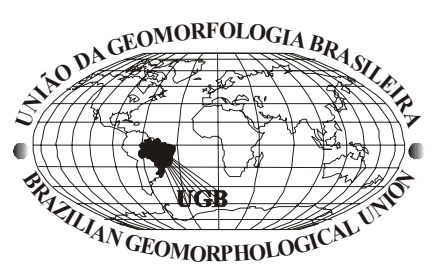

Revista Brasileira de Geomorfologia - Ano 7, $\mathrm{n}^{\circ} 2$ (2006)

\title{
OS PROCESSOS EROSIVOS LINEARES DA BACIA HIDROGRÁFICA DO RIBEIRÃO CARIOCA, ITABIRITO/MG E SEUS CONDICIONANTES PRINCIPAIS: OBSERVAÇÕES PRELIMINARES
}

\author{
Marcus Mergajeto Netto \\ Geógrafo, Mestre em Ciências Naturais - DEGEO - UFOP \\ mnetto@oi.com.br e/ou mnetto@click21.com.br \\ Frederico Garcia Sobreira \\ Doutor em Geologia - DEGEO/UFOP \\ sobreira@degeo.ufop.br
}

\begin{abstract}
Resumo
Na bacia hidrográfica do ribeirão Carioca, no distrito de São Gonçalo do Bação, Itabirito (MG), porção central do Quadrilátero Ferrífero, observa-se grande concentração de formas erosivas - ravinas e voçorocas - que alcançam dezenas de metros de profundidade e comprimento, responsáveis por problemas como o abandono do lugar, a deficiência da agricultura, perdas de terras e assoreamento de cursos d'água, provocando prejuízos econômicos, sociais e ambientais, para o poder público e a população em geral. Pretende-se, com o estudo, conhecer a disposição espacial de tais formas, bem como suas principais características, através da análise das características geomorfológicas da área com o intuito de compreender as ocorrências erosivas e contribuir para a identificação das fragilidades dos ambientes naturais da região. $\mathrm{O}$ trabalho resultou em um levantamento das feições erosivas existentes, distribuídas por toda área da bacia, segundo a compartimentação geológicogeomorfopedológica e distribuição altimétrica. $\mathrm{O}$ arranjo desses processos erosivos na região fornecem o cenário de uma paisagem degradada, além do risco instalado. Além disso, a contínua ação antrópica sobre o ambiente, desde três séculos torna evidente a necessidade de ações visando sua preservação e eventualmente sua recuperação.
\end{abstract}

Palavras-chave: ravinas e voçorocas; distribuição; condicionantes do meio físico.

\begin{abstract}
The Ribeirão Carioca's basin located in the district of São Gonçalo do Bação, Itabirito (MG), central portion of the Iron Quadrangle, presents a large concentration of erosive forms with some dozens of meters of large and deep. These erosive forms are responsible for problems such as abandonment of rural plots, agricultural deficiencies, losses of soil and the silt up of river courses, leading to economic, social and environmental losses for the public power and the population as a whole. This study aims to explore the spatial distribution of such forms, as well as their main characteristics, with the analysis of the geomorphologic profile of the area, to know the erosive processes and to contribute to the identification of environmental fragilities of the region. The work resulted in an inventory of the erosive forms, distributed throughout the entire basin area, according to the geologic-geomorphopedologic compartmentalization and altimetric distribution. The arrangement of these erosive processes in the region led to a highly degraded landscape and environmental risks. Besides, the continuous interventions upon the environment, for three centuries, make inevitable the creation of actions seeking the preservation and eventual recuperation of the area.
\end{abstract}

Keywords: gully erosion, distribuition, environmental factors of erosion. 


\section{Introdução}

A forma variada, rápida e agressiva como o homem tem interferido na dinâmica natural da Terra estimula a realização de estudos que apontem soluções para os inúmeros problemas que atingem o meio ambiente (Carpi Jr. 2001). Para tanto, uma das mais eficientes formas de se investigar a dinâmica do ambiente é tomar como unidade geográfica a bacia hidrográfica. No presente estudo destaca-se a erosão, que provoca a perda de solos agricultáveis e assoreamento dos cursos hídricos, dentre outros problemas.

Tais condições ocorrem na porção centro-sul do Complexo do Bação, na bacia hidrográfica do ribeirão Carioca (BHRC), onde se destaca uma grande ocorrência de processos erosivos na paisagem, que culminam em ravinas e, inclusive, extensas voçorocas ativas, que atingem profundidades de dezenas de metros, resultando em conseqüências danosas ao ambiente (Sobreira 1998; Costa \& Sobreira 2001). Em vários locais as erosões avançaram até quase o topo dos divisores, sendo separados apenas por estreitas faixas que representam as antigas cumeeiras.
Com este trabalho objetiva-se contribuir para a identificação das fragilidades do ambiente natural da região e suas relações com processos erosivos, os quais poderão subsidiar estudos visando o desenvolvimento sustentável da área.

\section{Área de estudo: aspectos gerais}

A área de estudo, bacia hidrográfica do ribeirão Carioca, situa-se entre as latitudes $20^{\circ} 16^{\prime} 45^{\prime \prime}$ e $20^{\circ} 22^{\prime} 30^{\prime \prime} \mathrm{Sul}$ e entre as longitudes $43^{\circ} 47^{\prime} 30^{\prime \prime}$ e $43^{\circ} 54^{\prime} 30^{\prime \prime}$ Oeste, no distrito de São Gonçalo do Bação, distante cerca de $15 \mathrm{Km}$ da sede do município de Itabirito/MG. Está inserida na porção central do Quadrilátero Ferrífero, zona metalúrgica de Minas Gerais e engloba o ribeirão Carioca e seus afluentes: Saboeiro, Olaria, Augusto e Felipe, com uma área de 65,9 Km² (Figura

Geologicamente, a bacia hidrográfica do Ribeirão Carioca (BHRC) faz parte de uma conhecida província geológica brasileira, o Quadrilátero Ferrífero, sendo na área estudada representada pelo Complexo Metamórfico do Bação,

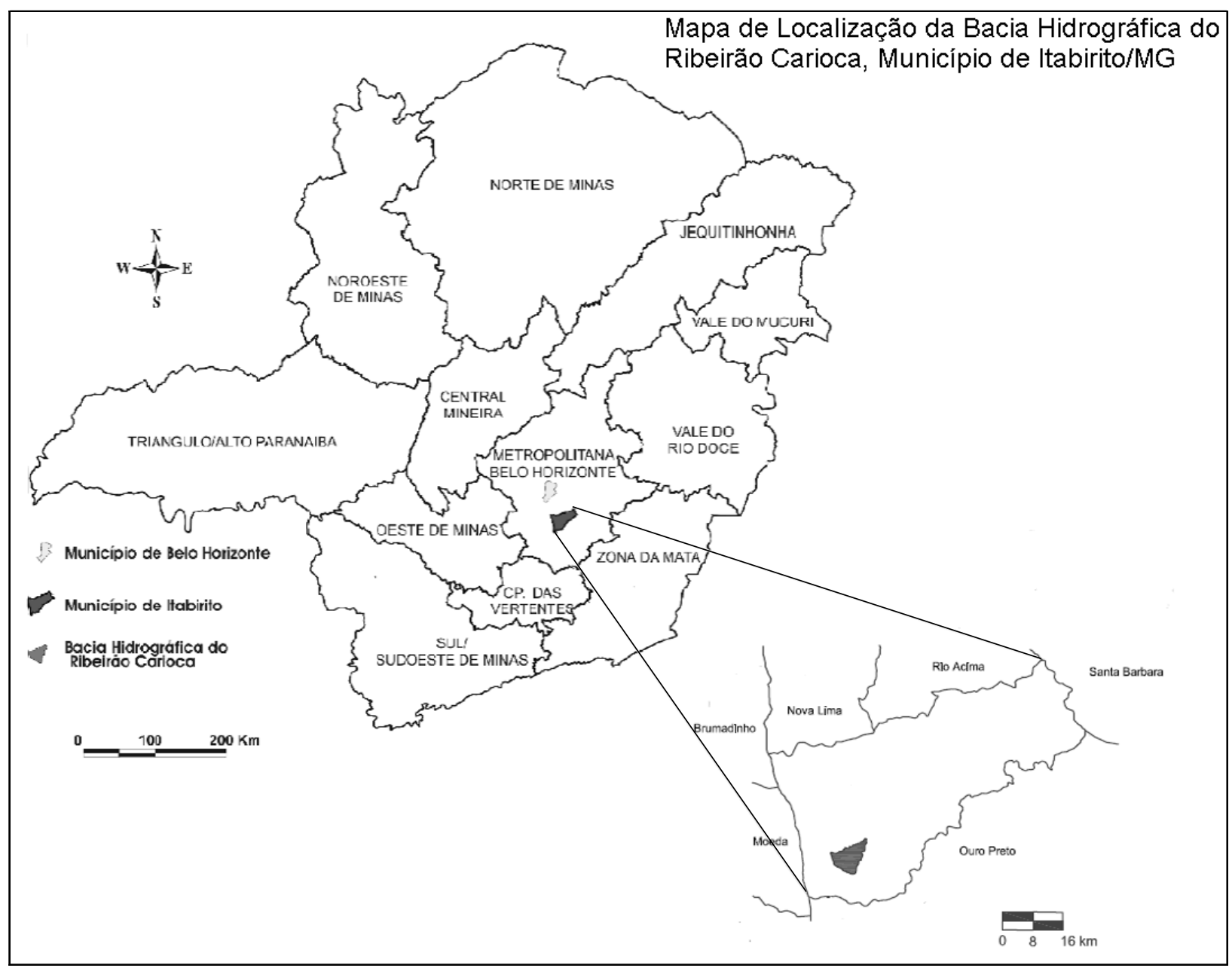

Figura 1 - Mapa de localização da bacia hidrográfica do Ribeirão Carioca 
o Supergrupo (Sg) Rio das Velhas e o Supergrupo (Sg) Minas (Alkimin \& Marshak 1998, Dorr 1969).

Geomorfologicamente, esta área posiciona-se nos limites de duas unidades geomorfológicas: Serra e Planalto da Moeda (W) e Depressão do Rio das Velhas (E) (IGA 1996).

A primeira, representada pelas denominações de serra das Serrinhas e serra do Saboeiro, têm como substrato as rochas do Sg Minas: quartzitos sericíticos, filitos, itabiritos, calcários, dolomitos ferruginosos e quartzitos (IGA 1996). Está formada por dois grandes alinhamentos paralelos de cristas estruturais e separadas por um planalto constituído por topos ondulados, altas colinas, escarpas e vertentes íngremes com alta declividade (superior a 30\%), onde as altitudes alcançam de 1400 a 1500 metros. (IGA 1996; Santos, Sobreira \& Netto 2004).

Na segunda unidade, conhecida como Depressão do Rio das Velhas (E), encontram-se rochas do Proterozóico representadas pelos xistos e filitos do Grupo Nova Lima e rochas do tipo granito-gnáissicas do embasamento do Arqueano, representado pelo Complexo Metamórfico do Bação (IGA 1996, Bacellar 2000). De topografia acidentada, caracterizada por um relevo de colinas côncavo-convexas e vales fortemente encaixados, além de vertentes ravinadas com altitudes médias de 1.000 metros. Ocorre ainda, uma forma de relevo com vales encaixados e topos aguçados com altitudes em torno de 1.100 e 1.200 metros, além de vertentes retilíneas, em muitos pontos ravinadas. Observa-se também um desnível topo-vale acentuado, que pode atingir cerca de 150 metros de desnivelamento, com declividades elevadas que alcançam de 20 a 30\% (Santos \& Sobreira 2005).
O ribeirão Carioca é tributário do rio Itabirito, que por sua vez é um dos afluentes da margem esquerda do rio das Velhas, pertencente à grande bacia hidrográfica do rio São Francisco, mais propriamente seu alto curso. A maioria dos córregos formadores da bacia hidrográfica do ribeirão Carioca têm suas nascentes na serra das Serrinhas, na faixa formada pelas rochas do Sg Minas (Grupos Caraça e Itabira), atravessam as rochas do Sg Rio das Velhas (Grupo Nova Lima), até sua foz no rio Itabirito, sobre o Complexo Metamórfico do Bação (Santos, Sobreira \& Netto 2004). Suas linhas de drenagem são condicionadas a um padrão dependente das estruturas regionais e ocorrem na direção SW-NE (Costa \& Sobreira 2001).

A região encontra-se sob o domínio do clima tropical de altitude (Cwa), segundo classificação de Köppen, caracterizado por invernos secos e verões brandos e chuvosos. A temperatura média anual oscila em torno de $17^{\circ}$ C. Nos meses mais frios as médias diárias situam-se entre $13^{\circ}$ e $15^{\circ} \mathrm{C}$ e nos meses mais quentes entre $20^{\circ}$ a $22^{\circ} \mathrm{C}$. Registrase uma sazonalidade bem marcada, com a estação chuvosa de novembro a abril e o período de estiagem de maio a outubro. A precipitação anual varia de 1.800 a 2.000 mm (IGA, 1996; Santos, Sobreira \& Netto 2004).

$\mathrm{Na}$ área da bacia hidrográfica do ribeirão Carioca, em função das rochas de composição granito-gnáissicas do Complexo Metamórfico do Bação, ocorre predominantemente o Latossolo Vermelho-Amarelo distrófico (LVAd4), além do Cambissolo Háplico (CXa), Afloramento de Rochas mais Neossolo Litólico (AR) e Neossolo Flúvico (RU) (Quadro 1). (CETEC 1983, EMBRAPA 1999, IBRAM 2003).

Quadro 1: Tipos e características dos solos da BHRC

\begin{tabular}{|c|c|c|}
\hline Tipo & Característica & Unidade \\
\hline LVAd4 & $\begin{array}{l}\text { Latossolo vermelho-amarelo distrófico mais cambissolo háplico } \\
\text { alumínico, ambos "A" moderado textura argilosa, fase floresta } \\
\text { subperenifólia, relevo ondulado e forte ondulado }\end{array}$ & $\begin{array}{c}\text { Complexo do } \\
\text { Embasamento Cristalino } \\
\text { (rochas granito-gnáissicas) }\end{array}$ \\
\hline $\mathrm{CXa} 3$ & $\begin{array}{l}\text { Cambissolo háplico alumínico mais latossolo vermelho-amarelo } \\
\text { distrófico, ambos "A" moderado, textura argilosa, fase floresta } \\
\text { subperenifólia, relevo forte ondulado e ondulado }\end{array}$ & $\begin{array}{c}\text { Complexo do } \\
\text { Embasamento Cristalino } \\
\text { (rochas granito-gnáissicas) } \\
\text { Sg Rio das Velhas (xistos) }\end{array}$ \\
\hline AR4 & $\begin{array}{l}\text { Afloramento de rochas mais neossolo litólico mais cambissolo } \\
\text { háplico, todos indiscriminados, fase campo rupestre, relevo } \\
\text { forte ondulado a montanhoso e ondulado (Grupo Itabira - } \\
\text { itabiritos e dolomitos) - (Grupo Caraça - quartzitos e filitos) }\end{array}$ & $\begin{array}{l}\mathrm{Sg} \text { Minas (itabiritos, } \\
\text { filitos e quartzitos) }\end{array}$ \\
\hline RUbe & $\begin{array}{l}\text { Neossolo flúvico eutrófico, "A" moderado, textura } \\
\text { indiscriminada, fase floresta subperenifólia de várzea mais } \\
\text { hidromórficos indiscriminados, fase campos de várzea, ambos } \\
\text { relevo plano a suave ondulado }\end{array}$ & $\begin{array}{l}\text { Complexo do } \\
\text { Embasamento Cristalino } \\
\text { (planícies aluviais) }\end{array}$ \\
\hline
\end{tabular}

Fonte: Modificado de EMBRAPA (1999) e IBRAM (2003). 
A vegetação da bacia hidrográfica do ribeirão Carioca situa-se numa zona denominada "Área de Tensão Ecológica" (IBGE 1996), que abrange parte de dois grandes biomas de Minas Gerais: a Mata Atlântica e o Cerrado. Parte de sua vegetação está classificada como Floresta Estacional Semidecidual submontana incluída no domínio da Mata Atlântica, em geral associadas a cursos d'água e se apresentam secundarizadas, uma vez que surge com o abandono da terra, após o uso pelas atividades mineradora e ou agrossilvipastoris ou o florestamento de áreas campestres naturais (IBGE 1991, IBGE 1992, RADAMBRASIL 1983). O Cerrado, por sua vez caracterizado pela presença de invernos secos e verões chuvosos (Ribeiro \& Walter 1998), situa-se entre campos limpos e os campos rupestres, mudando vez por outra a formação vegetal, quando adquire aspecto florestal, acontecendo de forma abrupta ou gradual, sendo geralmente a capoeira, a tipologia intermediária que dá o aspecto de transição, por ser um estágio sucessional da floresta semidecídua.

Quanto à ocupação do solo e organização do espaço, a região de estudo vive um momento controvertido, quando a economia agrícola local incipiente e expulsora de população simultaneamente experimenta um movimento inverso que se apropria do solo, parcelando-o e promovendo um "chacreamento" como objeto de lazer, muito em função da proximidade com Belo Horizonte, Itabirito e Ouro Preto.

\section{Material e Métodos}

Preliminarmente, foi realizado um levantamento bibliográfico sobre o tema, método e técnica de abordagem do problema e de informações sobre a área de estudo, o que permitiu um embasamento conceitual e teórico necessário à pesquisa. Seguiu-se o inventário e aquisição e análise das bases cartográficas, assim como de todo o material representativo e ilustrativo do meio físico, destacando-se o trabalho preliminar realizado por Costa \& Sobreira (2001), com base no qual foram realizadas tarefas de interpretação cartográfica e fotoanálise (1986, escala de 30.000), para reconhecimento da área de pesquisa e seus aspectos físicos, além da análise de ortofotos, escala de 1:10.000 (1986) (Santos, Sobreira \& Netto 2004).

Posteriormente, foi realizado o trabalho para levantamento das feições erosivas em campo, do tipo exploratório, com a observação das feições e relacionados seu registro em carta, plotando-se no mapa base cada feição erosiva, seu formato e o seu estágio de desenvolvimento. Por fim, procedeu-se à sistematização dos dados, segundo as características geológicas, geomorfológicas, pedológicas e altimétricas da unidade de trabalho. Assim, segundo o posicionamento de cada foco erosivo, o mesmo foi classificado consoante com cada uma das características elencadas.

No intuito de tornar compreensível o arranjo de tipos das feições erosivas estas foram categorizadas segundo seu estágio de evolução, tendo como base os trabalhos de Castro, Mello \& Peixoto (2002) e Sobreira (1998), definindo três grupos: ativas, em processo de estabilização e estabilizadas. As categorias de feições erosivas cadastradas na bacia foram representadas do seguinte modo:

1. Forma Ersosiva Ativa: Formas/feições erosivas com suscetibilidade de movimentos de massa rápidos ou não, independente de sua profundidade, alongamento e ramificações; conectada ou não à rede fluvial. Estas, são dinâmicas e susceptíveis de escorregamentos rotacionais ou translacionais, associados ao escoamento superficial concentrado e/ou sub-superficiais. Ocorrem ainda, os movimentos de "queda", que são movimentos rápidos de blocos ou lascas (placas) de rochas associadas a planos de fraqueza (desplacamento), não apresentando obrigatoriamente uma superfície de deslizamento.

2. Forma Erosiva Estabilizada: Formas/feições erosivas recobertas por vegetação natural, independente de sua profundidade, alongamento e ramificações; conectada ou não à rede fluvial. $O$ fato de que tais feições se encontrem estáveis e não apresentarem sinais de atividade ou reativação dos processos, não elimina possíveis reativações, dependendo apenas de eventuais fatores, principalmente antrópicos, como a retirada da cobertura vegetal, que possam vir a desencadear movimentos em planos de fraqueza do solo, gerando uma sinergia de mecanismos e o retorno do processo à atividade.

\section{Forma Erosiva em Processo de Estabilização: Formas/} feições erosivas que apresentam uma cobertura vegetal pouco desenvolvida, mas guardam ainda, pequena atividades erosiva, associando trechos já estabilizados, a outros em processo de estabilização, isto é, trechos da forma erosiva plenamente recoberta por vegetação natural a outro ainda descoberto, ou com cobertura incipiente. Tais feições são susceptíveis a movimentos de massa, podendo a qualquer instante, dependendo da ação dos agentes erosivos, retornar à atividade, caso ocorra retirada da vegetação ou outras ações humanas, sobretudo em sua área de contribuição ou captação.

Diante dos dados coletados foi possível elaborar o Mapa Cadastral dos Processos Erosivos da bacia hidrográfica do ribeirão Carioca, lançado originalmente em base cartográfica de 1:25.000, georreferenciada a partir das folhas de Itabirito e Barra do Gentio (DSG/Exército/SECT/IGA-MG, $1: 25.000,1986)$. Este mapa representa a distribuição das feições erosivas na área de estudo, além da sua classificação quanto ao seu atual estágio de desenvolvimento. 


\section{Resultados e Discussões}

O estudo da erosão dos solos implicou, necessariamente, no conhecimento das características geológicas, geomorfológicas, pedológicas, dos aspectos da vegetação e das condições climáticas da área de estudo, que condicionam o desenvolvimento de processos geodinâmicos, como movimentos de massa, erosão e transporte e deposição de sedimentos. Estes processos, quando ativos, podem causar inúmeros problemas ao uso e ocupação do solo. Por outro lado, as intervenções antrópicas inadequadas, como práticas de mineração e agrosilvipastoris, com a substituição da cobertura natural e alterações na rede de drenagem, geram condições facilitadoras para a deflagração e/ou ampliação de processos erosivos que originam ravinas e voçorocas.

$\mathrm{Na}$ bacia hidrográfica do ribeirão Carioca são observados processos erosivos muito atuantes, que constituem causa de muitos problemas relacionados ao uso da terra, além de promoverem a dissecação do relevo. Do arranjo morfológico de relevo movimentado, desenvolvido sobre as condicionantes litoestruturais, sobressaem os alinhamentos de cristas e escarpas de falhas, com níveis rebaixados intensamente dissecados. Esses ambientes caracterizam-se por uma intensa atividade de processos morfogenéticos, que prevalecem sobre os processos pedogenéticos, não obstante o adiantado estado de intemperismo de alguns tipos de rochas (IBRAM 2003).

A conformação do relevo na área da bacia de drenagem está caracterizada pela presença de dois domínios distintos (RADAMBRASIL, 1983). O primeiro, de ambientes serranos ou linhas de cristas e cumeadas, com altimetria elevada (1100 a 1400 metros) está associado a processos estruturais condicionantes da conformação do relevo tais como falhas normais e de empurrão e fatores litológicos, com a presença de solos pouco desenvolvidos e rarefação de vegetação. Nesta unidade foram mapeadas 7 feições erosivas, correspondentes a $5,56 \%$ do total da bacia hidrográfica. Dessas formas, 5 são ativas, 1 estabilizada e 1 está em processo de estabilização (Santos, Sobreira \& Netto 2004).

$\mathrm{Na}$ segunda unidade, abrangida pelo Complexo Metamórfico do Bação, está a maior parte da bacia e sua porção mais homogênea. Esse domínio caracteriza-se por relevos dissecados e por um espesso manto de alteração, com formas de relevo suavemente ondulado, vegetação degradada e intenso retrabalhamento das drenagens, resultando numa área de grande instabilidade ambiental. Essa unidade apresenta a maior concentração de ravinas e voçorocas e representam $94,44 \%$ dos processos erosivos da bacia, correspondendo ao total de 119 feições erosivas, sendo 46 formas ativas, 43 estabilizadas e $30 \mathrm{em}$ processo de estabilização. Constatou-se que a maioria está associada a atividades antrópicas, como as estradas e os divisores de propriedades (cercas, muros, valas, etc.).

$\mathrm{Na}$ distribuição total das formas erosivas da bacia hidrográfica do ribeirão Carioca foram identificadas 126 feições, entre ravinas e voçorocas. Dessas, 51 (40,48\%) foram classificadas como ativas, 44 (34,92\%) como estabilizadas e $31(24,60 \%)$ como em processo de estabilização (Tabela 1). Ao considerar as sub-bacias para efeito desta distribuição, observa-se que a maior parte das feições erosivas $(47,62 \%)$ encontram-se na sub-bacia do córrego Saboeiro, com um total de 60 feições, numa área de $19,0 \mathrm{Km}^{2}$. Seguem-se: a subbacia dos córregos Felipe e Augusto, com uma área de 16,8 $\mathrm{Km}^{2}$ e 29,37\% a sub-bacia do córrego Severino com a menor quantidade de feições, (7,94\%), numa área de $6,4 \mathrm{Km}^{2} \mathrm{e}$ finalmente, com uma área de $23,7 \mathrm{Km}^{2}$, o restante da bacia do ribeirão Carioca com 15,08\% do total de focos erosivos (Tabela 1).

As sub-bacias dos córregos Saboeiro e Felipe/Augusto juntas, respondem por 97 dos 126 feições existentes no total da bacia, ou seja, cerca de $77 \%$. Além disso, a sub-bacia do córrego Saboeiro concorre com o maior número de feições ativas (28), quase $60 \%$ do total dos focos presentes, além de 17 feições em processo de estabilização e 15 formas erosivas já estabilizadas. A sub-bacia dos córregos Felipe/Augusto possui um total de 37 focos erosivos, sendo 16 feições ativas, pouco mais de $30 \%$ do total, 11 em processo de estabilização e 10 estabilizados. Já a sub-bacia do córrego Severino, de menor área, possui o menor número de feições erosivas (10), sendo 2 ativas, 2 em processo de estabilização e 6 estabilizadas; finalmente, o ribeirão Carioca possui um total de 19 feições erosivas, sendo 5 ativas, 1 em processo de estabilização e 13 estabilizadas (Tabela 1 e Figura 2).

Tabela 1 - Distribuição das formas erosivas, segundo a Área e Sub-Bacias do Ribeirão Carioca

\begin{tabular}{lcccccc}
\hline \multicolumn{1}{c}{ Sub-bacia } & $\begin{array}{c}\text { Área } \\
\left(\mathbf{K m}^{2}\right)\end{array}$ & Ativas & Estabilizadas & $\begin{array}{c}\text { Processo de } \\
\text { Estabilização }\end{array}$ & Total & $\%$ \\
\hline Córrego Severino & 6,4 & 2 & 6 & 2 & 10 & 7,94 \\
Córrego Filipe/Augusto & 16,8 & 16 & 10 & 11 & 37 & 29,37 \\
Córrego Saboeiro & 19 & 28 & 15 & 17 & 60 & 47,62 \\
Ribeirão Carioca & 23,7 & 5 & 13 & 1 & 19 & 15,08 \\
\hline Total & 65,9 & 51 & 44 & 31 & 126 & 100 \\
\hline
\end{tabular}




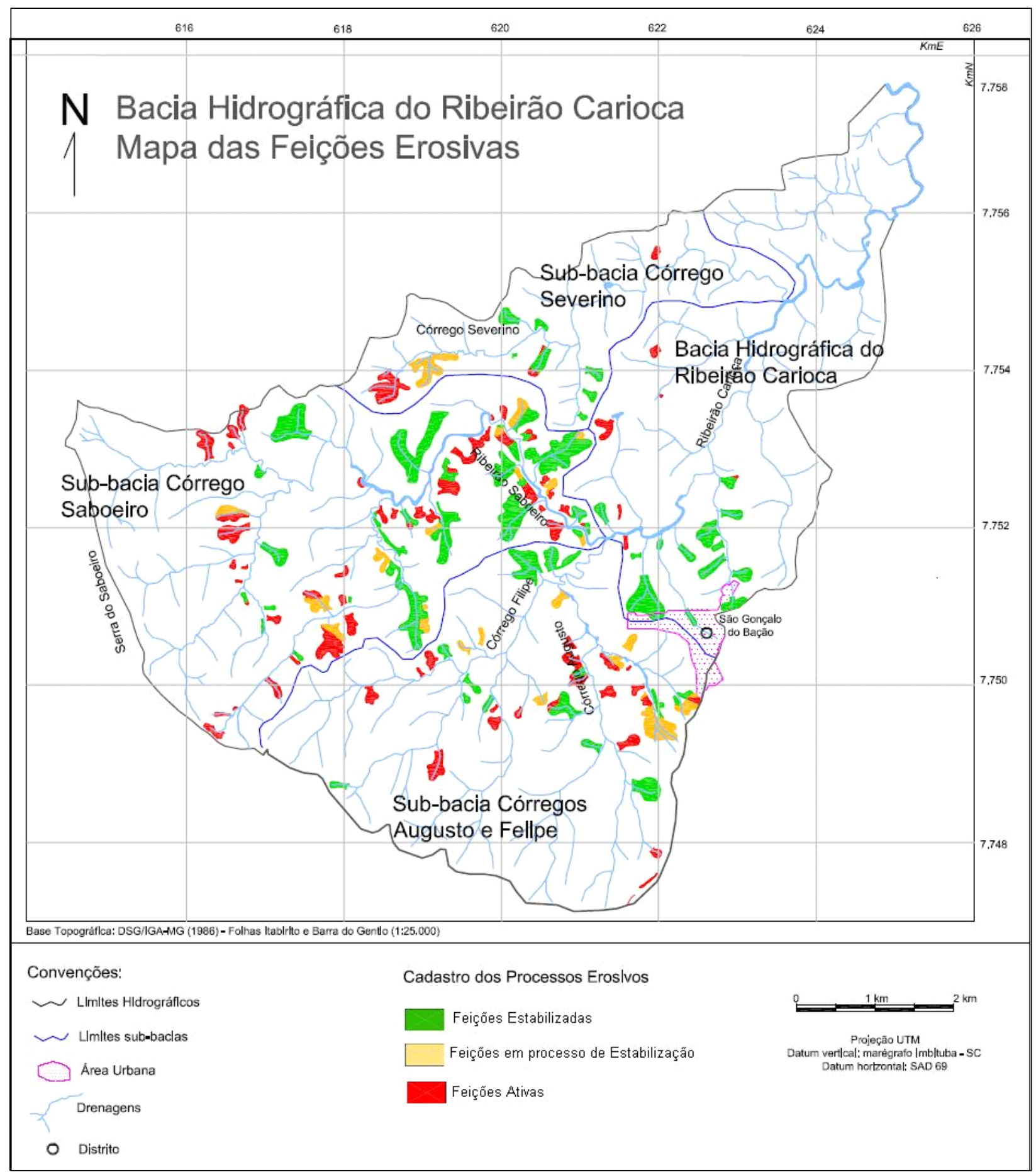

Figura 2 - Mapa do cadastro das feições/formas erosivas da BHRC

A bacia hidrográfica do ribeirão Carioca, com uma totalidade de 126 feições erosivas em $65,9 \mathrm{Km}^{2}$, apresenta, portanto, uma densidade de 1,91 feições erosivas $/ \mathrm{Km}^{2}$. Na sub-bacia do córrego Saboeiro encontra-se a maior densidade de feições erosivas $\left(3,32\right.$ feições erosivas $\left./ \mathrm{Km}^{2}\right)$, seguida pela sub-bacia do córrego Felipe/Augusto, onde ocorre uma densidade da ordem de 2,20 feições erosivas
$/ \mathrm{Km}^{2}$. Na sub-bacia do córrego Severino há uma densidade de 1,56 focos erosivos $/ \mathrm{Km}^{2}$, e, finalmente, na porção de jusante da bacia do ribeirão Carioca foi encontrado o menor valor, com 0,68 formas erosivas $/ \mathrm{Km}^{2}$. Tal fato relaciona-se à ocorrência de relevo menos movimentado e condições menos impactantes de uso da terra, com uma maior preservação da vegetação. 
Enfocando exclusivamente as feições erosivas ativas em relação à densidade de ocorrência, a sub-bacia do córrego Saboeiro apresenta a maior incidência, com 1,47 feições erosivas $/ \mathrm{Km}^{2}$, enquanto a bacia em sua totalidade possui 0,77 feições erosivas $/ \mathrm{Km}^{2}$; por outro lado, a sub-bacia do córrego Severino concorre com 0,31 feições por $\mathrm{Km}^{2}$, a subbacia Felipe/Augusto com 0,95 feições por $\mathrm{Km}^{2}$ e a área do restante da bacia com apenas 0,21 feições $/ \mathrm{Km}^{2}$.

Entretanto, em que pese a elevada densidade de feições erosivas na área, Melo (2004) afirma que apenas 3 novos focos erosivos foram registrados num intervalo de 36 anos (1950 - 1986) na sub-bacia do córrego Saboeiro. A autora também observa que as áreas abandonadas de mineração tornam-se mais propensas ao desenvolvimento dos processos erosivos, a partir do encerramento das atividades, quando há avanço dos processos erosivos em maior escala, fruto de um abandono irregular, sem as devidas adequações das cavas. Tais fatores apontam para os estudos de Sobreira (1998) e Bacellar (2000), que indicam haver passado o ciclo erosivo ou que o mesmo está em seu término, já que a maioria das formas em atividade resultam da intervenção humana nas últimas décadas.

Segundo os três domínios geológicos existentes na área de estudo é notória a predominância das feições erosivas no Complexo Metamórfico do Bação $(94,44 \%)$, não só pelas condições geológicas favoráveis ao intemperismo que a litologia apresenta (alterabilidade, condições de percolação de águas subsuperficiais), mas também pela extensão que ocupa na bacia. Nos demais domínios geológicos (Sg Rio das Velhas e Sg Minas) apenas 5,56\% do total de feições erosivas são observadas (Tabela 2).

Tabela 2 - Distribuição das formas erosivas da BHRC, segundo o domínio geológico

\begin{tabular}{lccccc}
\hline \multicolumn{1}{c}{ Bacia } & Ativos & Estabilizados & $\begin{array}{c}\text { Processo de } \\
\text { Estabilização }\end{array}$ & Total & $\%$ \\
\hline Complexo do Bação & 46 & 43 & 30 & 119 & 94,44 \\
SG Rio das Velhas & 5 & 0 & 1 & 6 & 4,76 \\
SG Minas & 0 & 1 & 0 & 1 & 0,80 \\
Total & 51 & 44 & 31 & 126 & 100 \\
\hline
\end{tabular}

Dos quatro tipos de solos encontrados, o Latossolo Vermelho-Amarelo distrófico (LVAd) é dominante, associado ao Complexo Metamórfico do Bação (Tabela 3), onde ocorrem 123 feições erosivas $(97,62 \%)$, sendo 49 focos ativos, 43 estabilizados e 31 em processo de estabilização. Essa classe favorece o desenvolvimento de processos erosivos lineares dada sua textura média, teor de argila dispersa relativamente elevado e moderado a fraco grau de desenvolvimento estrutural (Salomão, 1999).
Por conseguinte, sob o domínio do Cambissolo Háplico álico(CXa) ocorrem na área apenas 3 focos erosivos, sendo identificados como 2 formas ativas e uma forma estabilizada. Encontrado em parte, nos xistos do Sg Rio das Velhas e nos gnaisses do Complexo do Bação, estes solos têm sua ocorrência nas partes mais elevadas do relevo.

Vale ressaltar a importância que diz respeito à altimetria do terreno. Segundo levantamento realizado através das folhas topográficas (Folhas de Itabirito e Barra do Gentio

Tabela 3 - Distribuição dos formas erosivos da BHRC, por domínio pedológico

\begin{tabular}{lccccc}
\hline \multicolumn{1}{c}{ Tipo de solo } & Ativos & Estabilizados & $\begin{array}{c}\text { Proc } \\
\text { Estabilização }\end{array}$ & Total & \% \\
\hline Latossolo Vermelho-Amarelo & 49 & 43 & 31 & 123 & 97,62 \\
Cambissolo Háplico & 2 & 1 & 0 & 3 & 2,38 \\
\hline Total & 51 & 44 & 31 & 126 & 100,00 \\
\hline
\end{tabular}

(DSG/Exército/SECT/IGA-MG, 1:25.000 1986), o ponto de maior altitude da área de estudo está a $1358 \mathrm{~m}$, localizado na serra das Serrinhas e o ponto mais baixo está na foz do ribeirão Carioca a aproximadamente $820 \mathrm{~m}$ de altitude, portanto, uma amplitude 538 metros (Tabela 4).

Na distribuição das feições erosivas por cota altimétrica identificou-se que tais são estabelecidas a partir da isolinha de $950 \mathrm{~m}$, findando no limite de $1250 \mathrm{~m}$ (Tabela 4), numa amplitude de $300 \mathrm{~m}$. Essa distribuição ocorre com reduzido número de focos erosivos nas extremidades (cotas) altimétricas, porém este fato se deve mais às características litológicas e de uso do solo que propriamente a altitude, ou seja, rochas mais resistentes à erosão e ausência de presença antrópica nas partes mais elevadas. 
Tabela 4 - Distribuição das formas erosivas na BHRC, por altimetria e sub-bacias

\begin{tabular}{llccccccc}
\hline Bacia/Sub-bacia & Processo & $\begin{array}{c}\mathbf{9 5 0}- \\
\mathbf{1 0 0 0}\end{array}$ & $\begin{array}{c}\mathbf{1 0 0 0}- \\
\mathbf{1 0 5 0}\end{array}$ & $\begin{array}{c}\mathbf{1 0 5 0}- \\
\mathbf{1 1 0 0}\end{array}$ & $\begin{array}{c}\mathbf{1 1 0 0}- \\
\mathbf{1 1 5 0}\end{array}$ & $\begin{array}{c}\mathbf{1 1 5 0}- \\
\mathbf{1 2 0 0}\end{array}$ & $\begin{array}{c}\mathbf{1 2 0 0}- \\
\mathbf{1 2 5 0}\end{array}$ & TOTAL \\
\hline \multirow{3}{*}{ Córrego Severino } & Ativos & & 1 & 1 & & & & 2 \\
& Estab & & 6 & & & & & 6 \\
& Proc-Estab & & 1 & 1 & & & & 2 \\
Córregos & Ativos & & 6 & 6 & 2 & 2 & & 16 \\
Felipe/Augusto & Estab & & 5 & 4 & & & 1 & 10 \\
& Proc-Estab & & 9 & 2 & & & & 11 \\
Córrego Saboeiro & Ativos & & 6 & 7 & 6 & 7 & 2 & 28 \\
& Estab & & 4 & 4 & 3 & 4 & & 15 \\
Ribeirão Carioca & Ativos & 1 & 4 & & & & & 17 \\
(restante da bacia) & Estab & 2 & 9 & 2 & & & & 13 \\
& Proc-Estab & 1 & & & & & & 1 \\
\hline \multicolumn{2}{c}{ Total } & 4 & 59 & 32 & 13 & 15 & 3 & 126 \\
\hline
\end{tabular}

Grande parte das formas erosivas (59) ocorre na faixa de 1000 a $1050 \mathrm{~m}(46,83 \%)$, seguida pela faixa imediatamente superior (1050 a $1100 \mathrm{~m})$, com 32 formas $(25,40 \%)$. Na faixa de 1100 a 1150 m há 13 formas (10,32\%) enquanto na seguinte, (1150 a $1200 \mathrm{~m})$ ocorrem 15 feições erosivas $(11,90 \%)$. Segundo a tabela 4 , as faixas com menor ocorrência de formas erosivas estão justamente nos extremos, ou seja, na faixa entre 950 e $1000 \mathrm{~m}$ com 4 formas $(3,17 \%)$ e na faixa entre 1200 a $1250 \mathrm{~m}$ com 3 formas erosivas (2,38\%).

Segundo suas categorias e sub-bacias, em função da altimetria, as feições erosivas comportam-se da seguinte maneira: as formas erosivas ativas estão em maior número entre as faixas de 1050 a $1250 \mathrm{~m}$ (33 feições), enquanto as formas estabilizadas encontram-se em maior número nas faixas de 950 a $1050 \mathrm{~m}$ (24 feições). As feições em processo de estabilização não se destacam neste critério a não ser pela ausência de feições erosivas nas faixas de 1200 a $1250 \mathrm{~m}$.

Essa distribuição confirma os dados lançados anteriormente sobre os domínios geológicos, geomorfológicos e pedológicos. Assim as feições erosivas ocorrem em maior quantidade sobre o Complexo Metamórfico do Bação, em sua porção com morfologia mais suave e solos desenvolvidos (LVAd), enquanto que nas elevações a presença de processos erosivos é reduzida em função das características geomorfopedológicas, condicionados pelo relevo e substrato. Por outro lado, geomorfologicamente há que se considerar que as porções mais elevadas próximas aos divisores e cabeceiras de drenagem é que são alvo preferencial dos processos de dissecação.

\section{Conclusões}

Nesta pesquisa trabalhou-se no sentido de quantificar as feições erosivas existentes, de analisar sua distribuição, segundo sua categoria em termos de grau de desenvolvimento, domínio físico e sub-bacias da rede de drenagem do ribeirão Carioca. Foi possível concluir que a sub-bacia do córrego Saboeiro é a mais afetada pelas formas erosivas, onde ocorrem $47,62 \%$ do total de feições, sendo que ali encontra-se também a maior parte das feições ativas e estabilizadas, concorrendo com uma densidade de 3,32 feições erosivas $/ \mathrm{Km}^{2}$, enquanto na bacia total, a densidade alcança 1,91 feições erosivas $/ \mathrm{Km}^{2}$, entre ravinas e voçorocas, num total de 126 feições/formas erosivas.

Constatou-se que o Complexo Metamórfico do Bação concentra a maioria dos focos erosivos $(94,44 \%)$, bem como o Latossolo Vermelho-Amarelo (97,62\%) associado, e que a maior parte das formas erosivas ocorre na faixa dos $1000 \mathrm{a}$ 1050 metros (46,82\%). Justamente na área central da bacia, considerando a faixa de 1000 a 1100 metros encontram-se $72,22 \%$ do total de feições erosivas, num intervalo de aproximadamente 820 (oeste) a 1358 metros (leste).

Isto posto, deve-se considerar ainda, que os impactos decorrentes da atual situação da bacia hidrográfica do ribeirão Carioca, não podem ser atribuídos somente aos aspectos físicos, isto é, a sua susceptibilidade, mas decorrem de uma interação complexa de processos físicos e sociais, responsáveis pela aceleração do processo de dissecação da área, que ora parece estar se reequilibrando. Porém, a bacia é ainda frágil o que demanda mais pesquisas e ações no sentido de sua conservação. 


\section{Agradecimentos}

Os autores agradecem a FAPEMIG - Fundação de Amparo à Pesquisa de Minas Gerais pelo suporte financeiro na realização dos trabalhos.

\section{Referências bibliográficas}

Alkimin, F. F.; Marshak, S. (1998). Transamazonian Orogeny in the Southern São Francisco Craton Region, Minas Gerais, Brazil: evidence for Paleoproterozoic collision and collapse in the Quadrilátero Ferrífero. Precambrian Research, 90: 29-58.

Bacellar, L. A P. (2000) Condicionantes geológicos, geomorfológicos e geotécnicos dos mecanismos de voçorocamento na bacia do rio Maracujá, Ouro Preto, MG. 2000. 226 p. Tese de Doutorado. COPPE - Engenharia Civil, Universidade Federal do Rio de Janeiro, Rio de Janeiro/RJ.

Carpi Jr., S. (2001) Processos erosivos, recursos hídricos e riscos ambientais na bacia do rio Mogi-Guaçu. 170 p. Tese de Doutorado. Instituto de Geociência e Ciências Exatas, Universidade Estadual Paulista, Rio Claro/SP, 2001.

Castro, C. M.; Mello, E. V.; Peixoto, N. O. (2002) Tipologia de Processos Erosivos Canalizados e Escorregamentos - Proposta Para Avaliação de Riscos Geomorfológicos Urbanos em Barra Mansa. - RJ NEQUAT - Núcleo de Estudos do Quaternário e Tecnogeno). Instituto de Geociências da UFRJ Ilha do Fundão, RJ.

CETEC (1983) - Fundação Centro Tecnológico de Minas Gerais. Diagnóstico Ambiental de Minas Gerais. Belo Horizonte: Série de publicações técnicas/SPT -010 ISSN-0100-9540.58 p.

Costa, F. M.; Sobreira, F. G. (2001) Estudo Preliminar das voçorocas da bacia do Rio Carioca, Quadrilátero Ferrífero, MG. In: VII Simpósio Nacional de Controle de Erosão. Goiânia-GO, ABGE, CD Anais.

Dorr, J. N. (1969) Physiographic, stratigraphic and structural development of the Quadrilátero Ferrífero, Minas Gerais. U. S. Geol. Surv. Prof. Paper, v. 641-A, $110 \mathrm{~S}$.

DSG/Exército/SECT/IGA-MG. (1986) Folha Topográfica de Barra do Gentio. 1:25.000.

DSG/Exército/SECT/IGA-MG. (1986) Folha Topográfica de Itabirito. 1:25.000.

EMBRAPA. (1999). Sistema brasileiro de classificação de solos. Brasília: EMBRAPA, 412 p.
IBGE - Fundação Instituto Brasileiro de Geografia e Estatística. (1991). Classificação da vegetação brasileira, adaptada a um sistema universal. Rio de Janeiro: IBGE. 123 p.

IBGE - Fundação Instituto Brasileiro de Geografia e Estatística. (1992). Manual Técnico da Vegetação Brasileira. Rio de Janeiro: IBGE, 92 p.

IBGE - Fundação Instituto Brasileiro de Geografia e Estatística. (1996). Recursos naturais e meio ambiente: uma visão do Brasil. Rio de Janeiro: IBGE, $208 \mathrm{p}$.

IBRAM (2003) - Contribuição do IBRAM para o zoneamento ecológico-econômico e o planejamento ambiental de municípios integrantes da APA-SUL da RMBH - Itabirito-MG - memorial descritivo. Brasília: IBRAM.

IGA - Instituto de Geociências Aplicadas de Minas Gerais. (1996). Diagnóstico das condições físicoambientais e do potencial turístico do município de Itabirito-MG. Belo Horizonte: IGA.

Melo, M.C. (2004) Processos físicos e as alterações geomorfológicas recentes na sub-bacia do córrego do Saboeiro. 2004. 117 p. Dissertação de Mestrado. Universidade Federal de Ouro Preto, Ouro Preto/ MG

RADAMBRASIL. (1983) Levantamento de recursos naturais. Folhas SF 23/24. Rio de Janeiro/Vitória. Rio de Janeiro, v. 32, 767 p.

Ribeiro, J. F.; Walter, B. M. T.. Fitofisionomias do bioma Cerrado. In: Sano, S. M. \& Almeida, S. P. (Ed.) Cerrado: ambiente e flora. Planaltina: EMBRAPACPAC, 1998. p. 89-166.

Salomão, F. X. de T. (1999) Controle e prevenção dos processos erosivos. In: GUERRA, A. J. T. \& BOTELHO, R. G. M. (orgs.) Erosão e conservação dos solos. Rio de Janeiro, Bertrand Brasil,. p. 229 267.

Santos, C. A.; Sobreira, F. G. (Prelo) Cartografia geomorfológica no zoneamento territorial das bacias do ribeirão Carioca, córrego do Bação e córrego Seco, Itabirito/MG. Revista Brasileira de Cartografia. Vol. $\mathrm{xx}, \mathrm{n}^{\mathrm{o}} \mathrm{xx}, \mathrm{p} .: 00-00$.

Santos, C. A.; Sobreira, F. G.; Netto, M. M. (2004) Condicionantes do meio físico nas formas erosivas das bacias do Ribeirão Carioca, Córrego do Bação e Córrego Carioca, no município de Itabirito, MG. In: Simpósio Brasileiro de Cartografia Geotécnica e Geoambiental. 5. São Carlos/SP, ABGE, CD Anais.

Sobreira, F. G. (1998) Estudo das erosões do distrito de Cachoeira do Campo, Ouro Preto. Ouro Preto. Relatório Final de Projeto FAPEMIG/UFOP. 120 p. 